\title{
Profile of Released Guantánamo Detainees: The Government's Story Then and Now
}

\author{
Mark Denbeaux* \\ Joshua Denbeaux* \\ Adam Deutsch \\ David Gratz \\ Gabrielle Hughes \\ Michael Patterson \\ Paul Taylor
}

\section{Profiling the RELEASEd DetaineEs ${ }^{1}$}

In 2008, the Center for Policy and Research at Seton Hall University School of Law (the "Center") undertook to ascertain release data for detainees at Guantánamo Bay, Cuba, and compare that data to other variables in a search for correlations. This effort required analysis of numerous governmental sources. As documented in the Center's first report, A Profile of 517 Detainees Through Analysis of Department of Defense Data, the majority of detainees at Guantánamo Bay were never alleged to have committed hostile acts against United States or coalition forces, and $60 \%$ of all detainees were merely "associated" with al Qaeda or the Taliban. ${ }^{2}$ In order to determine who of the detainees were released and when they were released, the Center

* Professor, Seton Hall University School of Law, and Director, Seton Hall University School of Law Center for Policy and Research. The Report benefited from the research and contributions of Christopher Fox and Lauren Winchester.

** Partner, Denbeaux \& Denbeaux. Counsel to two Guantánamo detainees.

1 This Report, originally published on August 8, 2008, used government data obtained from Freedom of Information Act (FOIA) litigation. More information has been made available through later government releases and WikiLeaks. This Report was not updated based on WikiLeaks and later government releases. For future reports by the Seton Hall University School of Law Center for Policy and Research (the "Center"), visit the Center's website at http://law.shu.edu/ProgramsCenters/PublicIntGovServ/policyresearch/Guantan amo-Reports.cfm.

${ }^{2}$ See Mark Denbeaux et Al., A Profile of 517 Detainees Through Analysis of DEPARTMENT OF DEFENSE DATA 6 (2008), available at http://law.shu.edu/publications/guantanamoReports/detainees_then_and_now_fin al.pdf. 
gathered and reviewed data released by the Department of Defense. ${ }^{3}$ This data, which were produced either voluntarily or as the result of litigation and Freedom of Information Act (FOIA) requests by the media and other public interest groups, has enabled the Center to uncover the connection between the nationality of detainees, the allegations against them, and their release dates. At the time when the Report was written, enough information had been produced to compile a reliable profile of those detainees who were released from Guantánamo Bay.

\section{The DATA SOURCES}

The Center started with a review of an Associated Press FOIA request, which obtained a summary of classified evidence ("R1") regarding the status of detainees at Guantánamo Bay from the detainee's Combatant Status Review Tribunal (CSRT) hearings. ${ }^{4}$ The Center next considered documents released by the government on April 19, 2006, which showed the Internment Serial Numbers (ISN) along with the names of the 558 detainees who participated in CSRTs. ${ }^{5} \quad$ The Center reviewed documents released by the government on May 15, 2006, which listed the names of all 759 men who had been detained at Guantánamo. ${ }^{6}$ This latter list allows an inference that the 201 detainees who never participated in a CSRT were released or transferred at some point before the CSRT process began.

In addition, the Center reviewed the government-released Administrative Review Board (ARB) data. ${ }^{7}$ The ARB data determines whether detainees should continue to be detained, taking into account the findings of a detainee's CSRT. This information was then com-

\footnotetext{
${ }^{3}$ Because the method used to create the release model uses the date of the last recorded weight of the detainees as a criterion of release before November 2006, the three detainees who committed suicide in June 2006 are included among those considered released. Because this is a small percentage of those listed as released, the effect on any findings is minimal.

${ }^{4}$ For a list of the FOIA-released summaries of classified evidence see Combatant Status Review Tribunals (CSRT) and Administrative Review Board (ARB) Documents, U.S. DEP'T DEF., http://www.dod.mil/pubs/foi/operation_and_plans/Detainee/ csrt_arb/index.html (last visited Sept. 27, 2011) [hereinafter CSRT \& ARB].

${ }^{5}$ U.S. Dep'T of Def., List of Detainees Who Went Through Complete CSRT PROCESS (2006) [hereinafter CSRT LIST], available at http://www.dod.gov/pubs/foi/operation_and_plans/Detainee/detainee_list.pdf.

${ }^{6}$ U.S. Dep't of Def., List of Individuals Detained by the Department of Defense at Guantanamo Bay, Cuba from January 2002 Through May 15, 2006 (2006) [hereinafter LIST OF DETAINED INDIVIDUALS], available at http://www.dod.gov/pubs/foi/operation_and_plans/Detainee/detaineesFOIArelea se15May2006.pdf.

7 See CSRT \& ARB, supra note 4.
} 
bined with R1 data-the unclassified summary of the evidence for each detainee. Then, this data-set was cross-correlated with the dates and put together with the ISN, nationality, and the "profile" of the 558 detainees who received CSRT hearings. This Report relies on the government's contention that the R1 data presents a fair and accurate summary of the classified evidence as required by the FOIA. Finally, this Report also considered prior Center analysis, which broke down the allegations against each detainee in terms of hostile acts committed against United States or its coalition partners.

Complicating this effort was the failure of the Department of Defense to specify the release of detainees by ISN. The Center navigated this omission by reviewing the weight records of detainees. The Detention Hospital Guantánamo Bay, Cuba, Standard Operating Procedures ("Standard Operating Procedures") for the hospital at Guantánamo require that detainees be weighed once every month. ${ }^{9}$ Each weighing for a given individual was recorded by ISN. ${ }^{10}$ When weight data for a particular detainee stopped, the Center assumed that the detainee was released.

Yet, the weight data, which includes the ISN of the detainees, does not include the detainees' nationalities. Therefore, the Center cross-referenced the ISN with data released separately by the Department of Defense to determine the nationality of a given detainee. Together, this information yielded a picture of those being released and when they were released. Trends pertaining to the individuals' nationalities emerged showing that certain detainees were more likely than others to be released to particular countries. The Center also analyzed reports published by the Department of Defense concerning the times, dates, and descriptions of disciplinary violations. This additional information helped correlate the ISN and nationality information with the weight data.

${ }^{8}$ See Denbeaux ET AL., supra note 2. Though 516 detainees' R1 records were reviewed initially, another forty-two records were produced by the Department of Defense subsequent to the Center's initial report. As a result, the original numbers from the first report have changed slightly.

9 See Detention Hosp. Guantanamo Bay, Cuba, U.S. Dep'T Of Def., SOP No. 014: Detainee Weight Management and Nutrition Program 52 (2003) [hereinafter SOP No. 014], available

http://www.dod.gov/pubs/foi/operation_and_plans/Detainee/GITMO_MedicalSO Ps.pdf.

${ }^{10}$ For an index of the detainees' measurements see Other Detainee Related Documents, U.S. DEP'T DEF., http://www.dod.gov/pubs/foi/ operation_and_plans/Detainee/OtherDetaineeRelatedDocuments.html (last visited Sept. 27, 2011). 
Following a thorough review of the weight data, the Center considered additional information obtained by reviewing press releases by the Department of Defense. These announcements, which are freely available to the public on the Department of Defense website, contain information regarding the number of people released to each country, and in many cases, the basis for the release or transfer (i.e., CSRT, ARB, R1, etc.). ${ }^{11}$ This information was useful in a couple of ways.

First, Department of Defense announcements for 2005 and 2006 helped confirm release dates of many detainees, which were previously inferred from the last available weight data. The number of detainees released or transferred to a particular country, as announced by the Department of Defense, could then be compared with the weight data estimates of releases.

Second, the Department of Defense announcements helped supplement gaps in otherwise available information. Weight data for a period beyond early 2007 was not available, and even the data for late 2006 was not a wholly reliable indicator of release dates. As mentioned above, the Standard Operating Procedures mandate that detainees be weighed at least once every month. ${ }^{12}$ Yet, the data showed gaps in the weight measurements for some detainees that greatly exceeded this thirty-day period. The number of detainees released to specific countries in 2007 and early 2008 thus provided a more complete picture of how nationality was related to the release or transfer of individuals held at Guantánamo.

The weight data was also compared to variables that included the number of paragraphs in the charges against specific detainees in their R1 documents, the alleged association and the nexus of each detainee, and whether the detainee was charged with a hostile or non-hostile act. This comparison led to the finding that a detainee's alleged status as a "fighter for," "member of," or "associated with"13 either the Taliban or al Qaeda had little correlation with the likelihood that the detainee would be transferred or released.

${ }^{11}$ See, e.g., Press Release, Dept't of Def., Detainee Transfer Announced (Oct. 12, 2006), available at http://www.defense.gov/Releases/Release.aspx?ReleaseID=10068; Press Release, Dept't of Def., Detainee Transfer Announced (Oct. 16, 2006), available at http://www.defense.gov/releases/release.aspx?releaseid=10081; Press Release, Dept't of Def., Detainee Transfer Announced (June 19, 2007), available at http:/ / www.defense.gov/releases/release.aspx? releaseid=11030.

${ }_{12}$ See SOP No. 014, supra note 9.

13 See Denbeaux et AL., supra note 2, at 2. 
After comparing the alleged association and nexus of the detainees in R1 documents to their corresponding release dates, the Center juxtaposed this information against variables indicating the alleged level of danger of detainees used in a Pentagon-commissioned West Point study. ${ }^{14}$ This study evaluated the danger level of each detainee based on a review of the unclassified CSRT hearing summaries. ${ }^{15}$ A comparison of the data made evident that there was no correlation between a given detainee's dangerousness and the likelihood that the detainee would be released or transferred to another nation.

The Center's analysis reveals that the continued detention of some detainees in Guantánamo and the release of other detainees were decided without regard to the purported evidence and without regard to the factors identified in the Pentagon-commissioned West Point report. Instead, the constant factor was nationality. The fact that decisions correlate only with nationality suggests that they were based on political considerations, rather than on individual assessments of the evidence against each detainee.

\section{METHODOLOGY OF REPORT}

To estimate the release dates of detainees, the Center employed a model that combined information from the Department of Defense weight data, the Department of Defense press releases listing detainee releases and transfers, and CSRT and ARB information. ${ }^{16}$ Specifically, the date of a detainee's final weighing ("MaxDate"), along with the CSRT dates and ARB data, provided the information necessary to determine an initial approximate date of release. This initial date, along with a detainee's nationality, was compared to the information published in the Department of Defense press releases to match ISN information to the probable date of release. Since the Department of Defense did not usually provide information about the nationality of released detainees, the nation to which individuals were sent was used in lieu of nationality and then compared to the known nation of origin of the detainees. Because the data revealed that, on average, fiftyone days passed from the date of a detainee's last weighing to the

${ }^{14}$ Joseph Felter \& Jarret Brachman, Combating Terrorism Ctr., West Point, An Assessment of 516 Combatant Status Review Tribunal (CSRT) UnClassified SUMMARIES (2007), available at http://www.pegc.us/archive/Organizations/CTC_csrt_rpt_20070725.pdf.

15 See id. at 2.

${ }^{16}$ For the purposes of analysis, this Report accepts all government statements as true and complete, and assumes that R1s accurately represent summaries of the classified evidence against the detainees. The "Weight Data Identifier" from the database is on file with the Center. 
date of the detainee's release, a release date of fifty-one days after the final weighing was used for those detainees who were not matched to a press release.

\section{RELEASE OF DETAINEES FROM THE GUANTÁNAMO BAY DETENTION FACILITY: BY THE NUMBERS}

\section{A. Summary}

Documents released by the Department of Defense showed that the detention facility at Guantánamo Bay, Cuba, had held a total of 773 prisoners since early 2002..$^{17}$ The prisoners' nationalities represented forty-four countries. ${ }^{18}$ However, $75 \%$ of the detainees were from one of the following six countries: Afghanistan, Algeria, China, Pakistan, Saudi Arabia, and Yemen. Besides these six nations, no other country had accounted for more than $2 \%$ of the total detainee population. Prior to the end of 2006, 45\% (354 individuals) of all detainees were released from Guantánamo. In addition, 201 detainees did not undergo CSRT reviews. ${ }^{19}$ While the government did not provided meaningful information regarding these 201 detainees, all were released from Guantánamo Bay by November 2006. In addition, there were fourteen subsequent arrivals to Guantánamo Bay from CIA "black sites" for whom the Center does not have R1 summaries. ${ }^{20}$

For each of the remaining 578 detainees who underwent the CSRT process, substantial information is available regarding their alleged association with terrorist organizations, the alleged hostile acts they undertook, their weight data, and releases. ${ }^{21}$ The available data suggests that there is little correlation between the release dates for

17 List OF DETAINED INDIVIDUALS, supra note 6. The number is based on information as of May 2008.

18 See id.

19 See supra notes 4-6 and accompanying text. The number is based on information as of July 2008.

${ }^{20}$ Michael Melia, U.S. Military Rehearses Terror Hearings, WASH. PosT(Dec. 17, 2006, 7:43 PM), http://www.washingtonpost.com/wpdyn/content/article/2006/12/17/AR2006121700462.html.

${ }^{21}$ The Department of Defense produced the same R1 for two different detainees. Thus, the Department of Defense produced R1s for 557 of the 558 detainees who had CSRTs. The detainee whose R1 is missing is ISN 271, a Saudi national named Ibrahim Muhammed Ibrahim Al Nasir who was likely released on May 18, 2006. For public information on his release see Fourteen Guantanamo Detainees Returned to the Kingdom, SAUDI EMBASSY (June 25, 2006), http:// www.saudiembassy.net/archive/2006/news/page453.aspx (using the transliteration Ibraheem Mohammed Ibraheem Al-Nasser). 
detainees and their alleged commission of hostile acts or association with al Qaeda or the Taliban.

Of the 577 detainees for whom there were available profiles, those who were determined to have a relationship with a terrorist group were placed in one of the following classifications: "al Qaeda," "Taliban," "al Qaeda \& Taliban," "al Qaeda or Taliban," "none alleged," and "unidentified." 22 The nexus, or the type of relationship the detainees were alleged to have with these organizations, was further categorized as "associated with," "fighter for," "member of," and "none alleged.",

Of the released detainees, documents verify that 31 were released for further detainment abroad, 104 were released to foreign governments, 95 were released to freedom, and 3 were released for further prosecution.

In the case in which detainees were released to foreign governments, there was no specification as to their status following transfer. Thus, their fate and whereabouts presumably remain unknown to the U.S. government.

\section{B. Association and Nexus}

The CSRTs concluded that a total of 184 detainees were "associated with" al Qaeda. Of these detainees, forty-three, or $12 \%$ of the detainees released from Guantánamo, were "associated with" al Qaeda (27.6\% of all who participated in CSRTs). The majority of al Qaeda "associates" released from Guantánamo (twenty-five detainees) were transferred to the control of a foreign government. This means that the United States has relinquished control over these detainees and has left a foreign entity to determine their fate.

Of the 131 detainees allegedly "associated with" the Taliban, $39 \%$ (fifty-one detainees) were released. Among the released Taliban "associates," 22\% were released to freedom, while 59\% were transferred to the control of foreign governments. A total of 148 detainees were found to be "associated with" both al Qaeda and the Taliban, $22 \%$ of whom have been released from Guantánamo. Finally, of the thirty-nine detainees classified as "associated with" al Qaeda or the Taliban, $15 \%$ were released from Guantánamo.

Thus, detainees who were found to have a relationship with al Qaeda and/or the Taliban, but for whom the CSRTs did not determine conclusively with which group they were associated, were re-

22 See Denbeaux \& ET AL., supra note 2 , at 8.

${ }^{23}$ Id. at 9 . 
leased at a substantially greater rate than those who were conclusively found to be associated with al Qaeda.

Nearly $25 \%$ of the 321 detainees associated with one of these terrorist groups were released to freedom, while $52 \%$ were transferred to foreign governments. The government classified forty-nine detainees as having fought for the terrorists. Of these forty-nine detainees, either two or three were transferred to a foreign government for further detainment, while ten or eleven were transferred to foreign governments without specified conditions for their treatment, and two were released to freedom.

With respect to the detainees labeled as "members" of a terrorist organization, forty-five detainees $(28.8 \%$ of all detainees released from Guantánamo who participated in a CSRT) were found to be "members of" al Qaeda, the Taliban or both, $20 \%$ were released to freedom, and $69 \%$ were transferred to a foreign government.

There are ten detainees who were found to have a relationship with a terrorist group, but "no nexus" alleged. Of these ten detainees, nine were from Afghanistan. Finally, of the seventeen "fighters" released from Guantánamo, only one was released for prosecution.

\section{Little Correlation Between Nexus to Terrorist Activity} and Date of Release

Detainment periods show minimal correlation between release date and alleged terrorist activities. The median release dates of those detainees who were alleged fighters, associates, or members of a terrorist group varied by a single calendar day. Surprisingly, $50 \%$ of the detainees for whom there was no allegation of nexus or association were never released. Thus, they received treatment no different than the detainee who were found to be members of the Taliban or al Qaeda. The mean release dates show greater variation. The seventeen alleged fighters were released, on average, forty-three days earlier than the detainees who were merely associated with a terrorist organization and fifty-seven days earlier than those who were only members. These numbers contradict the common perception that a fighter poses a greater danger in the war on terror than does an associate or a member. ${ }^{24}$

${ }^{24}$ The Combating Terrorism Center (CTC) at West Point agrees with the assessment that fighters represent the most dangerous class of detainees. The CTC study requested by the Department of Defense found that "[e]vidence of performing the role of a fighter was-as expected - the most statistically and substantively significant predictor of . . . hostilities against the United States or Coalition Allies." FELTER \& BRACHMAN, supra note 14 , at 34 . The study also found that "[e]vidence of being a fighter boosts the chances of . . commitment to jihad by $16 \%$." Id. at 35 . 
Even as fighters were released at a greater rate than members or those simply associated with terrorist organizations, this increased rate of release had little demographic impact on the population held at Guantánamo. The proportion of alleged fighters dropped from $9 \%$ of all the detainees held at Guantánamo to $8 \%$ of those remaining when this Report was written in July 2008. Likewise, the percentage of members and associates did not change by more than a single percent. Based on this data, a detainee's nexus to a terrorist organization does not appear to have been a serious consideration in the decision to release the detainee or continue his detention.

\section{Little Correlation Between Association with al Qaeda} and/or the Taliban and Date of Release

There is surprisingly little correlation between association with a terrorist group and a detainee's release date from Guantánamo. On average, persons associated with al Qaeda were detained approximately two months longer than those associated with the Taliban. Persons associated with both al Qaeda and the Taliban were detained for almost identical periods of time as those who were only associated with al Qaeda. The persons detained the longest at Guantánamo were the thirty-nine detainees alleged to be associated with either al Qaeda or the Taliban. The government data suggests that it was uncertain with which group each detainee from that class was associated, but once a detainee's association was determined, the detainee's release followed shortly thereafter. For each of these groups, the median date of release lies on either November 19, 2006 or November 24, 2006. In other words, of those associated with any terrorist organization, $50 \%$ were never released. Viewing the data as demographic compositions of the yearly population at Guantánamo provides a different perspective on the picture that there was little or no distinction between the groups. The data shows that detainees were not treated according to the varying degrees of seriousness of their conduct or the different levels of potential danger, which depends on the terrorist organization with which the detainees were allegedly associated.

\section{Allegations of Hostile Acts Have Inverse Impact on Date of Release}

Of the 557 detainees who participated in CSRTs, $47 \%$ were accused of committing hostile acts. On average, those accused of hostile acts were released slightly later than those not accused of committing any hostile acts. This conclusion is supported by the fifty-nine- 
day difference in the mean MaxDate, and a sixteen-day difference in the mean release date. The larger difference in the mean MaxDate is due to the fact that, proportionally, more of the detainees who were not alleged to have committed hostile acts were released. This issue is addressed later in the Report.

As part of the CSRT process, detainees received summaries of the classified evidence, R1s, against them. ${ }^{25}$ Each of these documents included two paragraphs of allegations which supported the detainees' alleged association with and nexus to al Qaeda, the Taliban, or both, and any allegations of committed hostile acts. ${ }^{26}$ Paragraph $3 \mathrm{a}$ noted the detainees' association with a terrorist organization. ${ }^{27}$ The detainees received between zero and twenty-three counts supporting the claims of association. Any alleged hostile acts were noted separately, in Paragraph $3 \mathrm{~b}$ of the R1s.

At first, there appears to be a correlation between the number of 3a allegations made and the date of release; the detainees with fewer allegations were released earlier. Yet, this correlation is not significant because the number of allegations is normally distributed around 5.5. Those detainees receiving fourteen, fifteen, sixteen, twenty-three, and zero allegations constitute outliers, and are therefore not statistically significant. When these points are omitted, the apparent correlation falls apart. In fact, it appears that any correlation that does exist is inverse-the detainees with the most charges against them, presumably the most dangerous or, at least, the most likely to have been guilty, were released the earliest. The most common number of Paragraph 3a allegations was four; a total of $17 \%$ of the 557 detainees who underwent the CSRT process received four allegations. However, there were thirty-five detainees who received ten to thirteen allegations in their Paragraph 3a. Those detainees with the high number of counts were, on average, released before those who received only four counts. It appears that, in many instances, where more evidence existed to confirm the detainee's alleged association and nexus, the release rate was higher and occurred more quickly. Based on this finding, it appears that the government's evidentiary support for its allegations of a detainee's connection to a

${ }^{25}$ See, e.g., Unclassified Summary of Basis for Tribunal Decision, Hicks v. United States, No. 02-CV-0299 (D.D.C. Oct. 1, 2004), available at http://www.dod.gov/pubs/foi/operation_and_plans/Detainee/csrt_arb/publicly_fil ed_CSRT_records_1-91.pdf.

${ }^{26}$ See e.g., id. at 1-2.

${ }^{27}$ See e.g., id. at 1.

${ }^{28}$ See e.g., id. at 1-2. 
terrorist organization was not a serious or consistent consideration when determining whether to release or continue to detain the detainee.

The Paragraph 3b data presents a similar scenario. Initially, it may appear that detainees were detained longer than others when their R1s listed more allegations that supported claims of hostile acts, but this apparent correlation does not survive closer inspection. Of the 557 detainees for whom R1s are available, 295 were not alleged to have committed any hostile acts. For those who were alleged to have committed hostile acts, the number of allegations is normally distributed around 2.8. The categories farthest from the mean number of allegations, which represent a very small proportion of the population, are not significant. When those categories are removed from consideration-namely, those with six or more Paragraph $3 \mathrm{~b}$ allegations-the apparent correlation between fewer allegations and earlier release vanishes, and may in fact be reverse.

The reversal of the correlation is clear in that those detainees with two to five allegations of hostile activity were, on average, released between one and three months earlier than those who had only one allegation of hostile activity. Likewise, those with four and five allegations were released, on average, more than two months earlier than those with only one, two, or three allegations against them. These findings make clear that the government's own evidentiary support for its allegations of detainees' hostile acts had not been a factor seriously or consistently considered in the decision to release or continue detention of such detainees.

\section{CTC Factors Not Consistently Applied}

According to West Point's Combating Terror Center (CTC), detainees can be further categorized by a series of factors which measure the risk the detainees pose in the war on terror. ${ }^{29}$ The twelve factors are divided into three categories, with four factors in each: 1) "Level 3," ("Low Risk"), representing characteristics that demonstrate that a detainee is acquainted with dangerous persons; 2) "Level 2," ("Medium Risk"), suggesting that the detainee poses a probable risk; and 3) "Level 1," ("High Risk"), representing characteristics that the

${ }^{29}$ FELTER \& BRACHMAN, supra note 14 , at 4 . While the CTC factors are not an officially recognized evidentiary basis for detention, they were a system for analyzing the officially recognized R1s and were created at the behest of the Department of Defense. See id. at 2. If the R1s contain information that is used in the decision to release or to continue detention, correlation between the CTC factors and the date of release is to be expected. 
detainee poses a demonstrated risk. ${ }^{30}$ The CTC categorized 516 detainees based on the number of factors present at each risk level. ${ }^{31}$ As with the government's evidentiary factors, there appears to be a slight correlation between the CTC factors attributed to a detainee and the detainee's ultimate release date. The significance of this correlation, however, is very low.

As with the number of Paragraph $3 \mathrm{a}$ and $3 \mathrm{~b}$ allegations, there appears to be an inverse correlation with the release dates. Of the detainees who maintained two of the four risk factors, 123 detainees were placed in the High Risk group, ${ }^{32} 188$ were placed in the Medium Risk group, ${ }^{33}$ and 120 were placed in the Low Risk group. ${ }^{34}$ The mean release date for detainees with two risk factors was nearly identical at the Medium Risk and High Risk levels. These detainees were released on average thirty-six days earlier than those with two risk factors in the Low Risk category. Detainees with only two out of four risk factors at the Medium Risk and High Risk levels were also released on average before persons with three and four risk factors at the Low Risk level.

The release data for the detainees having three of the four risk factors mirrors the above finding. Detainees with three risk factors at the High Risk and Medium Risk levels were released approximately three weeks prior to those having three factors of Low Risk. In other words, the lower risk detainees were released on the same date and later than those to whom more factors applied. Among the detainees who had the greatest number of risk factors according to the CTC report, the more dangerous were released first. If the Medium Risk and High Risk levels represent the likelihood that a detainee poses a threat, one would think that these detainees would also satisfy categories in the Low Risk status, since the latter merely represents that a detainee knows dangerous persons. ${ }^{35}$ On the contrary, there appears to be little correlation between the CTC risk factors and a detainee's date of release. Yet, there is a correlation demonstrating that the more factors a detainee had and the greater danger a detainee represented, the sooner and the more likely it was that he be released from Guantánamo.

${ }^{30}$ See id. at 4-6, 10.

31 See id.

${ }^{32} \quad I d$. at 31 .

${ }^{33} I d$.

34 Id. at 32.

35 Felter \& Brachman, supra note 14 , at 10. 


\section{PATTERN OF RELEASE EXPLAINED BY NATIONALITY}

While the data demonstrates little or no correlation between the severity of the accusations against the detainees and their release date, one characteristic has shown significant correlation to the release dates: country of origin. Before explaining the significance of this correlation, however, it is important to define "release." While the definition might seem clear, the Department of Defense's data constructs a rather mottled interpretation. Of the detainees released up to November 2006, only $27 \%$ were officially released to freedom. Twenty-nine percent of the released detainees were released to foreign governments. Further 9\% were released for detention abroad and $1 \%$ were released for prosecution. Strikingly, $34 \%$ had no documented release category.

\section{A. Nations with High Numbers of Released Detainees}

\section{Afghanistan}

The data demonstrates what might be reasonably expectedthe country with the largest number of detainees is Afghanistan. ${ }^{37}$ Surprisingly, however, nearly $70 \%$ of those detained from Afghanistan were released by November 2006 . As indicated by the mean release date of March 30, 2005, the release of Afghan detainees was steady from the beginning of 2003. Of the released Afghan detainees, fifty-seven participated in CSRTs, 32\% were alleged to have committed hostile acts and $65 \%$ were alleged to be connected to al Qaeda, the Taliban, or both. Only 1\% of the released Afghan detainees were sent to Afghanistan for continued detention. A significant percentage $(42 \%)$ were not released for continued detention but to freedom.

\section{Pakistan}

Of the six countries representing more than $2 \%$ of the population in Guantánamo, the nation with the greatest number of released detainees is Pakistan, with sixty-one of sixty-six detainees released. ${ }^{38}$ However, over $67 \%$ of the Pakistanis released who participated in CSRTs were alleged to have committed hostile acts. Furthermore, over $40 \%$ of all those released were sent back to Pakistan for continued detention. As we have seen, in contrast, only $1 \%$ of Afghan de-

\footnotetext{
${ }^{36}$ Charts and descriptions reviewing the breakdown of releases from the nations with the most detainees in Guantánamo are on file with the Center.

37 See List OF DETAINED IndividuALs, supra note 6.

38 See id.
} 
tainees who were released were sent to Afghanistan for continued detention. The majority of Pakistani detainees were released relatively quickly, with a mean release date of July 2004.

\section{Saudi Arabia}

Saudi Arabia was unique among the top six countries in that it is the only one with a high release rate that has not seen $50 \%$ of its detainee population released as of November 2006. In 2007, sixty-three additional detainees were released to Saudi Arabia. Assuming that a majority of the released were Saudi nationals, more than half of the Saudi detainees had been released as of the end of 2007. The data set depicted in this Report, however, takes into consideration the data as of November 2006.

\section{B. Nations with Low Numbers of Released Detainees}

The Department of Defense data reveals that the detainees from certain nations' are less likely to be released from Guantánamo than the detainees of other nations. This is most clearly supported by the release rates of Yemeni and Algerian detainees.

1. Yemen

A total of eight out of 108 Yemeni detainees were released. ${ }^{39}$ Compare this to a release rate of $94 \%$ for the Pakistani detainees. Additionally, only two of the 108 Yemeni detainees were released to freedom. ${ }^{40}$ Thus, only $1.8 \%$ of Yemeni detainees attained freedom, compared to $42 \%$ of Afghan detainees. The reason for the disparate treatment is not clear because there is no significant difference in the accusations against the two groups. One theory is that the higher percentage of hostile acts alleged against Yemeni detainees-62\% compared to a total detainee population average of $47 \%$-caused their continued detention. This is disproved, however, by the counterexample of Algeria, with an average of hostile acts alleged in only $36 \%$ of the cases.

\section{Algeria}

Like the Yemeni detainees, only $4 \%$ of Algerian detainees were released. Despite the fact that Algerian detainees had the lowest per-

${ }^{39}$ As of July 2008, the Center identified these detainees as Walid Mohhamed Shahir, Karam Khamis Sayd Khamsan, Ali Abdullah Ahmed, Ali Husayn Abdullah AlTays, Issam Amid Al Bin Ali Al Jafi, Mahsin Mohammad Masheen Mobil, Mohammed Ahmed Ali Al Asadi, and Saleh Mohamed Al Zuba.

${ }^{40} I d$. 
centage of alleged hostile acts among the groups at Guantánamo, an Algerian detainee was twenty-four times less likely to be released than a Pakistani detainee. In addition, unlike detainees from countries such as Saudi Arabia, Algerian detainees' conditions for release were not documented.

\section{China}

The Chinese detainees represent a special case. All detainees of Chinese nationality were ethnic Uighurs, an Islamic minority from western China. ${ }^{41}$ The Department of Defense has admitted that the Uighurs are not, and never were, a threat to the United States or the coalition forces in Afghanistan. ${ }^{42}$ Yet, they could not return to China. ${ }^{43}$ Thus, five of the twenty-two Uighurs were released to Albania. ${ }^{44}$ However, as of the time when this Report was compiled in July 2008, the other sixteen Uighurs remained detained at Guantánamo, ${ }^{45}$ despite the lack of any basis for detention. Indeed, while $45 \%$ of all detainees had been released, $73 \%$ of the Uighurs remained confined.

Comparing release rates of these nations strongly indicates that many detainees are being released on the basis of nationality alone. Conversely, many detainees for whom little or no evidence exists were still being held after five years of detention. This disparity of treatment is evident in the demographic makeup of the Guantánamo population when viewed on an annual basis.

\section{Nationality Groups Confirm that Political Distinctions Drive the Release Decisions}

Of the 381 detainees from nations where Arabic is an official language, only eighty-nine detainees $(23.4 \%)$ were released as of the end of 2006. This is significantly lower than the $45.8 \%$ of all combined detainees who were released during the same period. The late release dates are also in stark contrast to the release dates of detainees from the other major nationality groups. Of the thirty-three detainees from post-Soviet nations, fifteen $(45.5 \%)$ were released by of

${ }^{41}$ Ishaan Tharoor, A Brief History of the Uighurs, TIME.cOM (July 9, 2009), http://www.time.com/time/world/article/0,8599,1909416,00.html.

${ }^{2}$ After Detention, Where Can the Uighurs Go?, N.Y. Times (Mar. 31, 2009), http://roomfordebate.blogs.nytimes.com/2009/03/31/after-detention-where-canthe-uighurs-go.

43 Id.

${ }^{44}$ Detainee Transfer Announced, U.S. DEP'T DEF. May 05, 2006, available at http://www.defense.gov/Releases/Release.aspx?ReleaseID=9527.

${ }^{45}$ As of 2011, there are only five remaining Uighurs detained at Guantánamo. Editorial, Every Zone, WASH. Post, May 24, 2011, at A20 . 
the beginning of 2007. In fact, all but one of these detainees was released prior to the CSRT process. Meanwhile, from the twenty-four detainees who were citizens of traditional United States' allies, all but three were released as of 2007. Comparing the mean release dates of these three groups cements the picture: on average, citizens of traditional United States' allies were released one year earlier than citizens of post-Soviet nations, who were, in turn, released, ten months prior to Arab nationals.

The post-Soviet group itself represents a microcosm of the entire population. Of the thirty-three detainees in this group, only the Russians and the Tajiks were released in large proportions. While 70\% of the Russians and Tajiks were released, only one of the eight Uzbeks was released, and none of the Azerbaijanis, Kazakhs, or Turkmens were released. Once again, stark differences in treatment between nationalities can be seen, which far outweigh the differences in treatment based on individualized evidentiary factors.

\section{The Special Case of Afghanistan}

The data indicates that detainees from Afghanistan were released the fastest and the most frequently of all the detainees held in Guantánamo. Well over two-thirds of all detainees from Afghanistan were transferred or released by late 2006 . Of this number, over $42 \%$ were released to freedom. The proportion of Afghans released to freedom or transferred, compared to detainees from all other nations, shows that an Afghan national had the best chance of being released. This discovery is interesting in light of the "Fact Sheet" dated June 13, 2008 published by the Department of Defense. ${ }^{46}$ This publication claimed that the former detainees "known or suspected of returning to terrorist activities" transferred to Afghanistan and Pakistan have generally reengaged in local, anti-coalition activity. ${ }^{47}$ Of the ten people listed in this release, six are from Afghanistan. Despite this claimed recidivism on the part of Afghans formerly detained at Guantánamo, Afghans represent the greatest number of those released to freedom.

\footnotetext{
${ }^{46}$ U.S. DeP'T OF Def., FACT Sheet: Former GTMO Detainee Terrorism TrendS (2008), available http:/ /www.defense.gov/news/d20080613Returntothefightfactsheet.pdf.

${ }^{47}$ See id.
} 
E. Nationality, Not Alleged Level of Danger, Determines Chance of Release

Although there may be other explanations, the Department of Defense has yet to offer them. Absent such an explanation, the conclusion seems inescapable-the detainees' country of origin, not their alleged degree of danger, was what determined their chance of release.

\section{ANY CORRELATION BETWEEN RELEASE DATE AND GOVERNMENT} EVIDENCE IS A RESULT OF THE GOVERNMENT'S DECISION TO RELEASE BASED UPON NATIONALITY

The slight correlations between release date, nexus, association, and hostile acts can be explained by reviewing the composition of those factors by nationality. The mean release dates show that fighters were released slightly earlier than members or associates, while those with no alleged nexus were released significantly earlier than those with a nexus. However, of the ten detainees not alleged to have any nexus, nine were Afghan. Afghans, overall, are released much earlier than other nationalities. Because Afghans make up only 28\% of the total population, the early release of the detainees who fall in the "none-alleged" category is a result of the fact that they were predominantly Afghan. For it to be otherwise, the Afghan population in Guantánamo would have to be proportionate to the percentage of detainees without any alleged nexus: $90 \%$. In comparison, of the forty-nine detainees alleged to be fighters, more than $50 \%$ were Afghans, Pakistanis, and Saudis, and were released much earlier than the "fighters" who belonged to the other top six nationalities. Meanwhile, only $16 \%$ of the "fighter" category, $24 \%$ of the "associated with" category, and $26 \%$ of the "member" category were Yemeni and Algerian nationals.

While Yemeni and Algerian nationals represented 133 detainees in Guantánamo, only nine were released. This implies that the slight correlation between nexus and release date is likely a product of random sampling within nationalities, rather than a secondary criterion of release. In addition, the slight correlation between association and release date is similarly a product of nationality. As with nexus, $90 \%$ of the ten detainees not alleged to be associated with any organization are Afghan. Thus, their earlier release is not a product of a lack of association, but rather the product of their nationality.

The slightly earlier release of those associated with the Taliban, relative to those associated with al Qaeda, al Qaeda and the Taliban, and al Qaeda or the Taliban, can also be explained by national com- 
position. Yemeni and Algerian nationals combined represent only $17 \%$ of the Taliban category, while together they represent $31 \%$, $25 \%$, and $35 \%$ of the al Qaeda, the al Qaeda and the Taliban, and the al Qaeda or the Taliban categories, respectively. Meanwhile, 38\% of the Taliban category consists of Afghan nationals, compared to $3 \%, 20 \%$, and $15 \%$ of Afghans in the other categories. Thus, the relatively early release of the Taliban is likely a product of the distinct treatment of Afghans as compared to Yemenis and Algerians.

In fact, the slight correlation between association and release date would likely be much stronger if it were not for the contribution of the Saudis. The Taliban category consists of $22 \%$ Saudis, the al Qaeda consists of 30\%, the al Qaeda and the Taliban consist of 27\%, and the al Qaeda or the Taliban consists of only 13\%. Though Saudis are released earlier than Yemenis and Algerians, they still have a median MaxDate of November 19, 2006. This date, later than the date for Afghans, mitigates the average release dates.

The fifty-nine-day difference in mean MaxDate between those who were and those were not alleged to have committed hostile acts is also likely a product of nationality. The proportion of Yemeni in each category is most salient here: Yemenis made up 25\% of the detainees alleged to have committed hostile acts, but only $14 \%$ of those who were not alleged to have committed any hostile acts. Conversely, Afghans made up $24.5 \%$ of those who were not alleged to have committed hostile acts, and only $20 \%$ of those who were. Saudis again played a mitigating role, contributing $26 \%$ of the detainees alleged to have committed a hostile act, and $21.5 \%$ of those who were not.

Because the correlation between the average release date and each of these factors is explainable as a product of the nationalities in each category, these correlations are not causal in nature. Therefore, this leaves nationality as the only known causal factor that determines the date of release.

\section{CONCLUSION-EVIDENCE AgAinst DetaineES WAS Not USED TO JUSTIFY CONTINUED DETENTION}

A review of the Department of Defense's own data reveals that there was not a consistent practice of releasing detainees based on their alleged association with al Qaeda and/or the Taliban. In addition, the number of charges against any given detainee did not seem to affect the detainee's release date. Instead, the only constant factor that had correlation to detainees' earlier release was the nationality of those released. A finding that nationality had the only causal relation to release date shows that either the Department of Defense 
never believed their own allegations for the basis of detention, or that they knowingly released individuals they believed to be dangerous. 